\title{
Action OF ADRENALIN ON THE CIRCULATION OF the MURINe Plasmodium DEVEloping STAGES, IN DIFFERENT BLOOD COMPARTMENTS
}

\author{
BERTANI S.*, GANTIER J.C.**, CHABAUD A.* \& LANDAU I.*
}

\begin{abstract}
Summary :
Adrenalin was used to investigate in vivo the circulation of the different stages of rodent Plasmodium present in the blood. A single dose of adrenalin injected to mice infected with $P$. yoelii resulted immediately in i) a diminution of the parasitaemia of approximately $50 \%$ in the peripheral large vessels (estimated in tail blood films), as well as in the capillaries (estimated in smears of blood collected from a fed Anopheles), and ii) an increased parasitaemia in blood collected by cardiac puncture from the right heart. The numbers of young stages of $P$. yoelii in the peripheral blood were initially somewhat reduced but, unexpectedly, midterm trophozoites were preferentially expelled from the peripheral blood into major organs like the heart. With P. vinckei, parasitaemia decreased only when midterm trophozoites predominated, and with $P$. chabaudi no effect was observed at any time. We propose that midterm trophozoites, by their increased surface area, as compared to rings, and their flexibility which contrasts with the rigid schizonts, are particularly susceptible to haemodynamic perturbations.
\end{abstract}

KEY WORDS : adrenalin, rodent, Plasmodium, circulation, erythrocytic stage blood compartment.
Résumé : ACTION DE L'ADRÉNALINE SUR LA CIRCULATION DES STADES ÉRYTHROCytaIRES DES PLASMODIUM DE RONGEURS DANS DIFFÉRENTS COMPARTIMENTS SANGUINS

L'adrenaline a été utilisée sur des souris infectées par Plasmodium murins pour étudier in vivo la circulation des différents stades sanguins. Une dose unique d'adrénaline injectée à des souris infectées par $P$. yoelii a été suivie immédiatement par 11 une diminution d'environ $50 \%$ de la parasitémie dans les vaisseaux périphériques, aussi bien de grand calibre lestimée dans les frottis de sang de la queve) que dans les capillaires (estimée dans les frottis de sang prélevés par des Anophèles), et 2l une augmentation de la parasitémie dans le sang prélevé par ponction cardiaque du coeur droit. Le nombre de stades jeunes de P. yoelii dans le sang periphérique a d'abord diminué, puis, de façon inattendue, les trophozoiltes moyens ont été expulsés préférentiellement du sang périphérique vers les organes vitaux. comme le coeur. L'adrénaline injectée à différents moments du cycle sur $P$. vinckei a entraîné une diminution de la parasitémie uniquement lorsque les trophozoites moyens prédominaient, alors qu'aucun effet n'a été observé sur $P$. chabaudi quel que soit le stade majoritairement présent. Les auteurs proposent l'hypothèse selon laquelle la surface des trophozoiltes moyens présente une meilleure prise au courant que celle des anneaux et que leur consistance est plus souple que celle - rigide - des schizontes. Les trophozoïtes moyens seraient, pour ces raisons, particulièrement sensibles aux perturbations hémodynamiques.

MOTS CLÉS : adrénaline, rongeur, Plasmodium, circulation, stade erythrocytaire, compartiment sanguin.

system are irregular, and vary according to the parasitic stage and the size, etc. of the blood vessels of the host (Desowitz et al., 1976; Marchiafava \& Bignami, 1982; Coquelin et al., 1999; Landau \& Chabaud, 2002). Several factors are involved: $i$ ) rheological, including the diameter and resistance of the vessels, the viscosity of the blood, and the rapidity of the blood flow; ii) peculiarities of the parasitized red blood cell: modifications of its physical properties (increased size and rigidity) induced by parasite development, sequestration in the venules, cytoadherence to the vascular endothelium or to intact erythrocytes (rosetting), etc...

Changes in the parasitaemia and the characteristics of parasitic infection were observed under conditions of stress and after treatment with pentoxifylline, a drug that increases red blood cell deformability and causes peripheral vasodilatation. The results indicated that 
later parasite stages became less abundant in the tail blood of mice (Voza et al., 2001).

Brumpt frequently used adrenalin injections to provoke a recrudescence of the infection in birds naturally infected with malaria parasites. The method was known in human medicine as "test d'adrénalino-réaction" or "spléno-contraction adrénalinique" (Brumpt, 1949), and was used as a diagnostic method to detect cryptic infections. The mechanism was thought to be due to a contraction of the smooth muscles expelling the parasitized erythrocytes from the spleen and their appearance in the circulating blood, within half an hour after injection of the drug. However, the method was considered to be dangerous and inefficient, and was abandoned (Bruce-Chwatt, 1986).

Adrenalin was used in the present work to induce a violent contraction of the peripheral vessels, thus modifying the distribution of the parasites. Blood from three types of vessels was examined:

- large peripheral blood vessels, obtained by cutting off the tip of the tail of mice;

- peripheral capillary blood, obtained by smearing the stomach contents of a female Anopheles immediately after a blood meal (Landau et al., 1979; Landau \& Chabaud, 2002);

- cardiac blood, obtained by puncture of the right heart.

\section{MATERIALS AND METHODS}

\section{BIOLOGICAL MATERIAL}

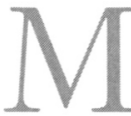
ice: female outbred OF1 IOPS mice (IffaCredo) weighing 20-25 grams kept under a rhythm of 12 hours light/ 12 hours dark.

Parasites: three parasite species isolated from wild Thamnomys rutilans trapped in the Central African Republic:

- P. yoelii yoelii strain 17X, clone 1,1 ;

- P. vinckei petteri strain 106 HW;

- P. chabaudi chabaudi strain 864 VD.

Mosquitoes: Anopheles stephensi bred in the laboratory.

\section{EXPERIMENTAL PROCEDURES}

Adrenalin doses of $1 \mathrm{mg} / \mathrm{kg}$ were injected subcutaneously to mice while control animals received the same volume $(0.1 \mathrm{ml})$ of saline. Tail blood films from mice were prepared just before and one minute after the injection and, in one experiment, after 10, 20 and 30 minutes. Heart blood was drawn by cardiac puncture of the right heart under ketamine anaesthesia $(20 \mu \mathrm{l}$ given intramuscularly). Smears from fed mosquitoes were prepared as follows: mosquitoes with swollen abdomens were removed from the mice while finishing their blood meal. The abdomen was squashed imme- diately and the blood smeared. The mean parasitaemia and parasitic pattern of five sequential smears were calculated.

Except when daily injections of adrenalin were given, all experiments were carried out when the parasitaemia was approximately $2 \%$ before heavy pathological changes occur in the host.

The following quantities were determined: $i$ ) parasitaemia; ii) parasitic pattern, i.e. percentages of the following parasitic stages: rings + young trophozoites (Rs + YTs), midterm trophozoites (MTs), old trophozoites (OTs), polyparasitized erythrocytes (PPs), schizonts (Ss) and gametocytes (Gs).

Parasitic patterns are expressed as the product of the parasitaemia and the percentage of each stage present.

\section{STATISTICAL ANALYSIS}

The distribution of the values obtained in a frequency histogram and a graph of the accumulation of frequencies demonstrated that our results, in both treated and control groups of mice, were normally distributed. The variance did not differ significantly between the groups. The significance of any differences obtained between experimental groups was evalued by Fisher's $t$-test (comparison of means). In all statistical analyses, significance was assessed at the $P<0.05$ level.

\section{RESULTS}

\section{EFFECT OF ADRENALIN ON RETICULOCYTES}

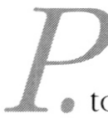
yoelii preferentially invades reticulocytes. A preliminary experiment was therefore performed to establish the effect of adrenalin on these cells twelve uninfected mice with a reticulocytaemia approximating $1.6 \%$ were injected with adrenalin and blood films were prepared before and one minute after the injection. There was no significant difference between the mean reticulocytaemia before treatment $(1.66 \% \pm$ 0.13 standard error $[\mathrm{SEM}])$ and after treatment $(1.63 \% \pm$ $0.1)$.

\section{P. YOELII YOELII: EFFECT ON THE TAIL BLOOD OF A SINGLE INJECTION OF ADRENALIN}

- Immediate effect

Twelve mice with parasitaemias of $1-2 \%$ on the fourth day after inoculation were treated with adrenalin and 12 control mice with saline. Blood films prepared just before and one minute after the adrenalin injection revealed a statistically significant decrease of parasitaemia $(\sim 50 \%)$. Parasitaemias in control mice remained constant (Fig. 1). Analysis of parasitic pattern at one minute after treatment showed a diminution of Rs + YTs, MTs and PPs, the effect being more pronounced $(\sim 70 \%)$ with MTs. 
The numbers of OTs was not significantly modified. Ss and Gs were too rare to be taken into account (Fig. 3, before and one minute after adrenalin injection).

- Duration of the effect

Six mice with parasitaemias of $1-2 \%$ on the fourth day after inoculation were treated with adrenalin. Tail blood films were obtained before and one, 15 and 30 minutes after the adrenalin injection. Progressive return to the initial parasitaemias (Fig. 2) and parasitic patterns (Fig. 3) occurred within 30 minutes.

\section{- Daily injections}

Twelve infected mice were given daily injections of adrenalin (six mice) or saline (six controls) at fixed times, starting at day 0. Blood films obtained before each injection showed no difference between control and treated mice. Films made one minute after treatment showed a significant drop of parasitaemia only when the latter was lower than $5 \%$, i.e. at the begin-

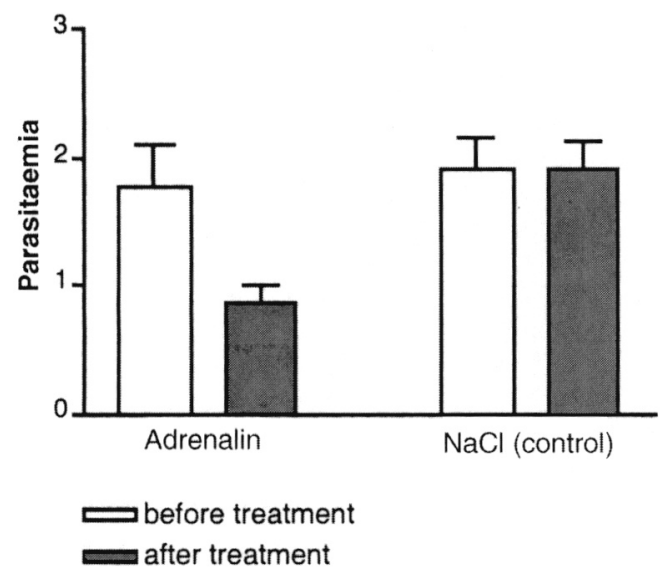

Fig. 1. - P. yoelii yoelii: immediate effect of adrenalin injection on parasitaemia in mouse tail blood.

Box-plots represent parasitaemias and vertical bars indicate the upper limit of the standard error of the mean (SEM).

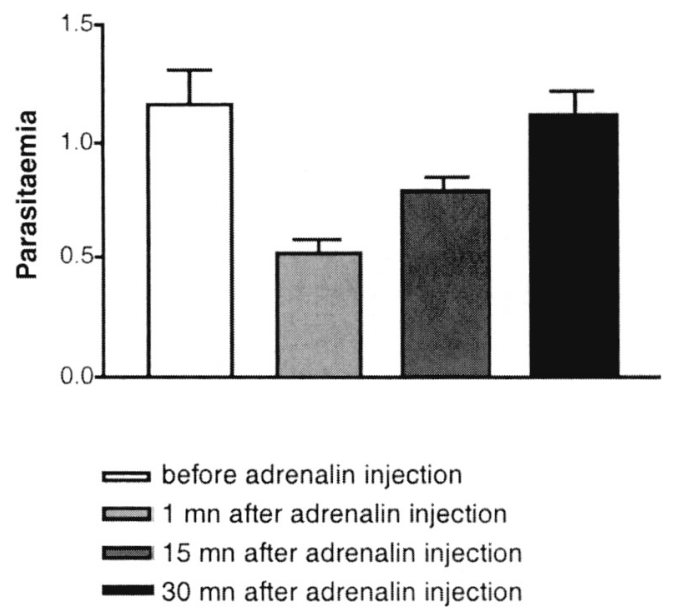

Fig. 2. - P. yoelii yoelii: effect of adrenalin on parasitaemia during 30 minutes following injection.

Box-plots represent parasitaemias and error bars indicate the SEM. ning of the patent period (until day 6 after inoculation) and after the crisis (from day 14 after inoculation).

\section{P. YOELII YOELII: EFFECT OF ADRENALIN ON CAPILLARY BLOOD}

Six mice with parasitaemias of 1-2\%, four days after inoculation, were exposed to mosquitoes for 20 minutes just before and for 20 minutes immediately following adrenalin injection. Tail blood films and mosquito blood meal smears were prepared according to the diagram (Fig. 4).

\section{- Parasitaemia (Fig. 5)}

Before adrenalin injection, parasitaemias were comparable in mouse blood and in the mosquito blood meals; after treatment they both decreased similarly.

- Parasitic pattern (Fig. 6)

In contrast to the stability of parasitaemias, parasitic patterns differed markedly between mice and mosquitoes.

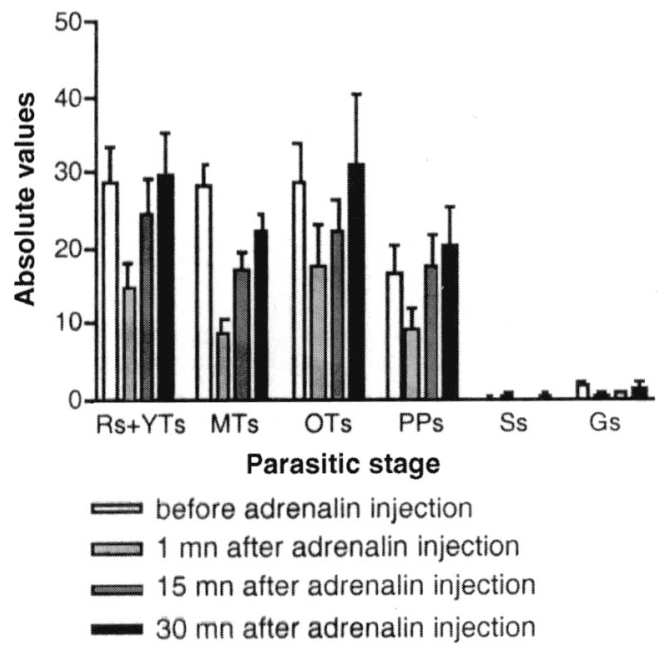

Fig. 3. - P. yoelii yoelii: effect of adrenalin on the parasitic pattern during 30 minutes following injection.

Box-plots represent absolute values of parasitic stages and error bars indicate the SEM.

Rs: rings; YTs: young trophozoites; MTs: midterm trophozoites; OTs: old trophozoites; PPs: polyparasitized erythrocytes; Ss: schizonts; Gs gametocytes.

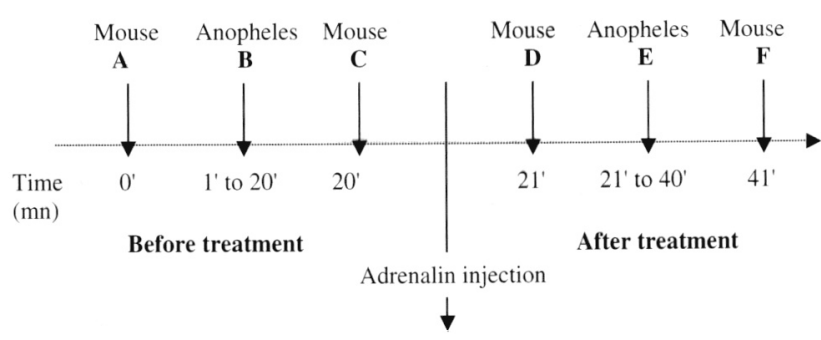

Fig. 4. - Protocol for comparing mouse tail blood with blood drawn from capillaries by mosquitoes.

Tail blood films (A, C, D, F) and mosquito blood meal smears (B, E) were prepared before (A, B, C) and after (D, E, F) adrenalin injection. Values in mouse tail blood before (A) and after (C) mosquitoes were fed were similar. 

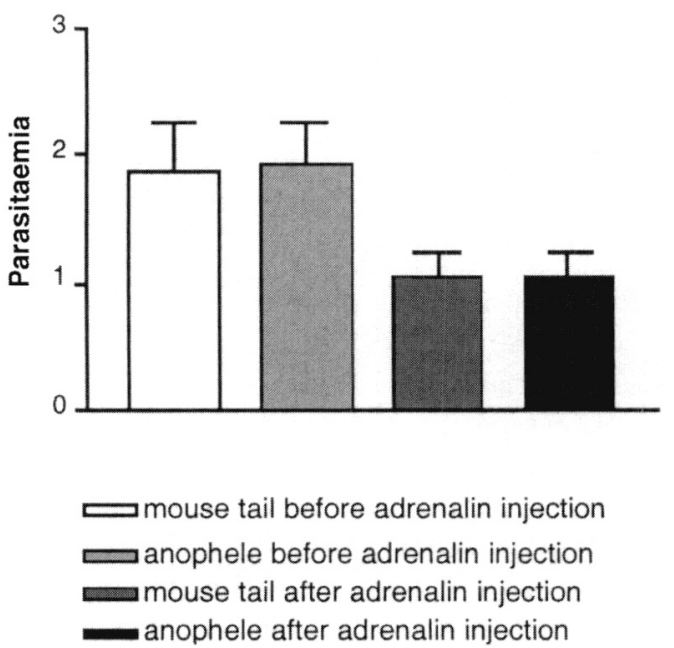

Fig. 5. - P. yoelii yoelii: effect of adrenalin injection on capillary blood parasitaemia.

Box-plots represent parasitaemias and error bars indicate the SEM

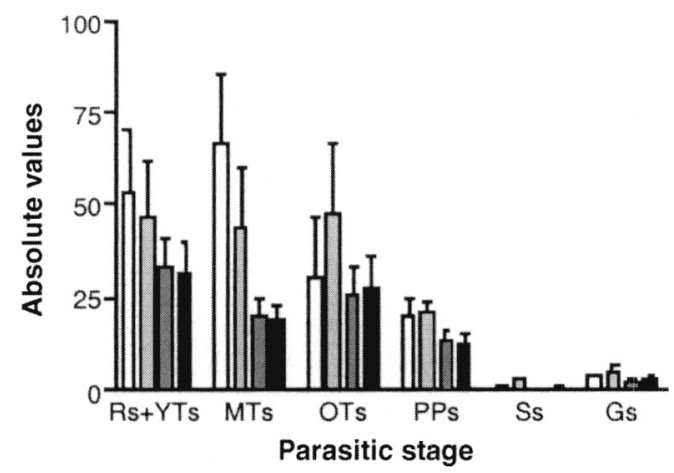

$\smile$ mouse tail before adrenalin injection

$\smile$ anopheles before adrenalin injection

- mouse tail after adrenalin injection

anopheles after adrenalin injection

Fig. 6. - P. yoelii yoelii: effect of adrenalin injection on the capillary blood parasitic pattern.

Box-plots represent absolute values of parasitic stages and error bars indicate the SEM

Abbreviations as in Figure 3.

Before adrenalin treatment, OTs were more numerous in the mosquito blood meals than in the tail blood of mice (representing capillary blood), but MTs were more numerous in the latter than in the former. Numbers of Rs + YTs and PPs were identical in the two blood preparations. During the 20 minutes following adrenalin injection, parasitic patterns were almost identical in mice and mosquitoes. There was a decrease of Rs + YTs, MTs and PPs in both preparations; however, in contrast to the situation in mice, OTs also decreased in mosquitoes.

\section{P. YOELII YOELII: EFFECT OF ADRENALIN ON INFECTED CELLS IN CARDIAC BLOOD}

Twelve mice with parasitaemias of 1-2 \%, four days after inoculation, were anaesthetized with ketamine. A

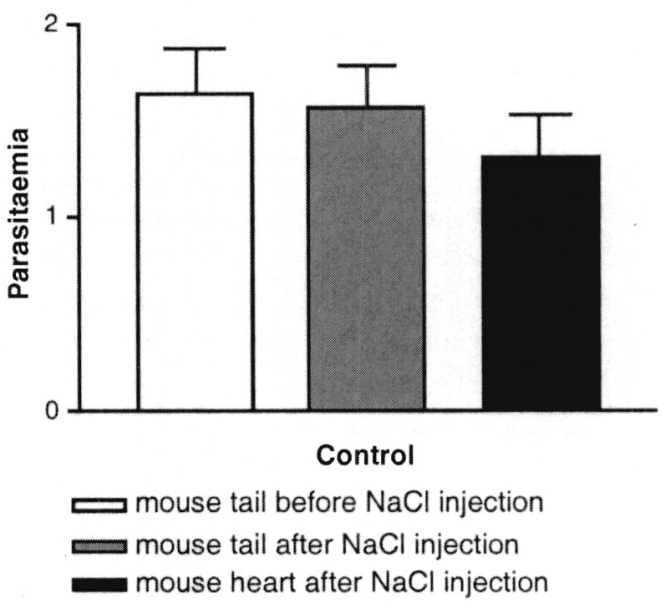

Fig. 7. - P. yoelii yoelii: effect of $\mathrm{NaCl}$ injection on mouse heart blood parasitaemia (control)

Box-plots represent parasitaemias and error bars indicate the SEM

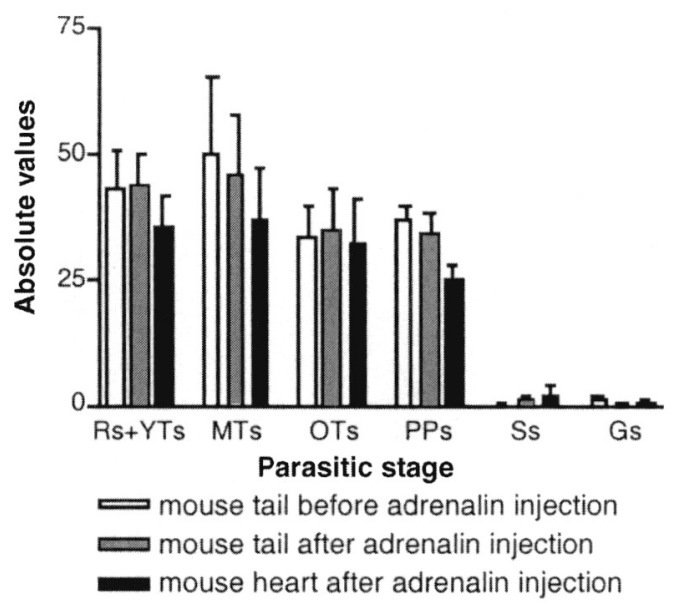

Fig. 8. - P. yoelii yoelii: heart blood parasitic pattern in control mice. Box-plots represent absolute values of parasitic stages and error bars indicate the SEM.

Abbreviations as in Figure 3

preliminary experiment had shown that the anaesthetic did not modify the parasitaemia or the parasitic pattern. Tail blood films were prepared before and one minute after injections of adrenalin to six mice and saline to six other control mice. Blood from the heart. was then immediately drawn from all mice and films were prepared.

In control mice parasitaemias and the parasitic patterns in tail blood were identical before and after saline injection. Heart blood, however, differed from tail blood: parasitaemias of control mice were lower than in tail blood and Rs + YTs and MTs were less numerous (Figs 7,8).

In mice treated with adrenalin, the usual decrease of parasitaemia and modification of the parasitic pattern (Fig. 9) were seen in tail blood; in contrast, parasitaemias increased in heart blood, as did the numbers of Rs + YTs and MTs. The parasitic pattern (Fig. 10) 


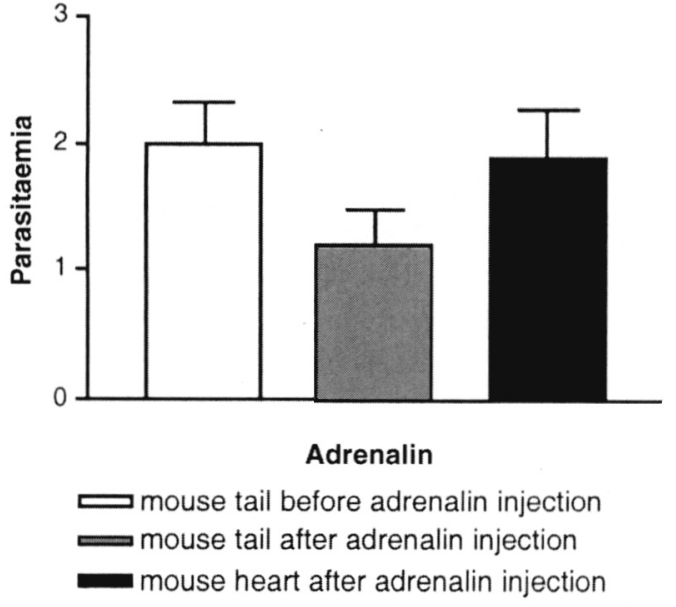

Fig. 9. - P yoelii yoelit: effect of adrenalin injection on mouse heart blood parasitaemia.

Box-plots represent parasitaemias and error bars indicate the SEM.

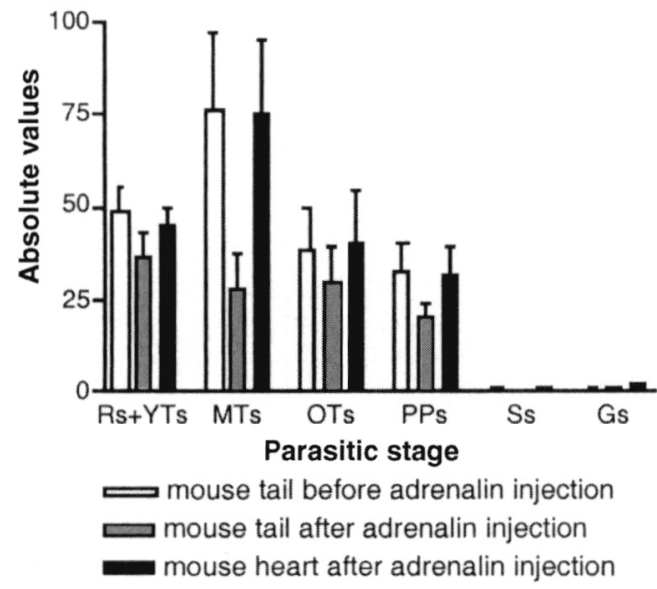

Fig. 10. - P. yoelii yoelii: effect of adrenalin on the parasitic pattern in mouse heart blood

Box-plots represent absolute values of parasitic stages and error bars indicate the SEM.

Abbreviations as in Figure 3

had become identical to that in mouse tail blood before the adrenalin injection.

\section{P. VINCKEI PETTERI: EFFECT ON THE TAIL BLOOD OF A SINGLE INJECTION OF ADRENALIN}

Thirty mice were infected at the same time of day $\left(t_{0}\right)$ with frozen aliquots of $P . v$. petteri, which is a synchronous species with a schizogonic rhythm set by the time of inoculation (Montalvo Alvares et al., 1988). The experiment was performed at day seven after inoculation. Adrenaline or saline were injected to experimental or control mice respectively at different times of day, six hours apart, when different parasitic stages were predominant: $i$ ) at $t_{0}$, when Rs + Ss were predominant together with many OTs, $i i)$ at $t_{6}$ when YTs were predominant, and iii) at $t_{12}$ when MTs were pre-

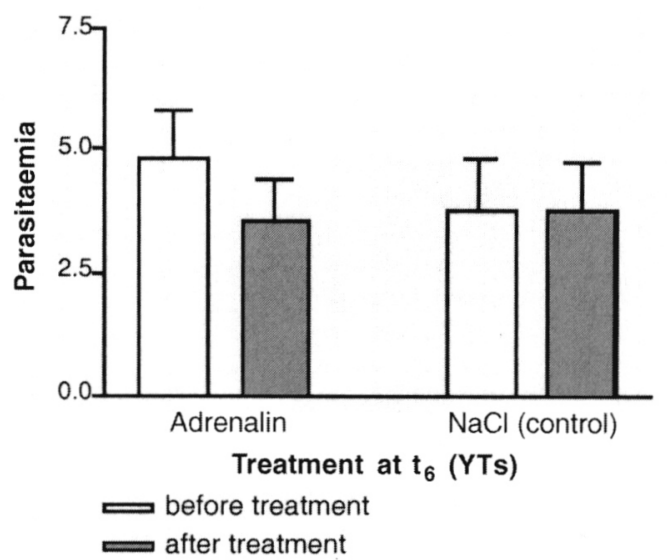

Fig. 11. - P. vinckei petteri: effect of adrenalin injection on parasitaemia in mouse tail blood when young trophozoites (YTs) are predominant $\left(t_{6}\right)$.

Box-plots represent parasitaemias and error bars indicate the SEM

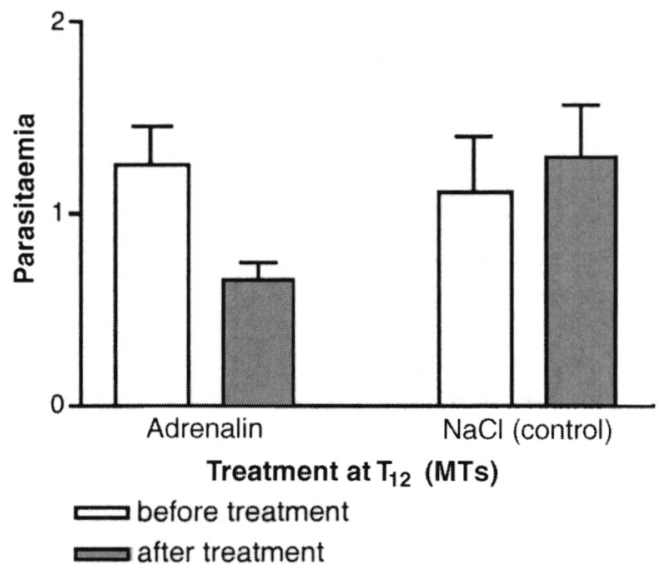

Fig. 12. - P. vinckei petteri: effect of adrenalin injection on parasitaemia in mouse tail blood when midterm trophozoites (MTs) are predominant $\left(t_{12}\right)$.

Box-plots represent parasitaemias and error bars indicate the SEM.

dominant. Parasitaemias were estimated in tail blood before and one minute after the injections.

Parasitaemias decreased by approximately $20 \%$ when adrenalin was injected in mice with a predominance of YTs $\left(t_{6}\right)$ (Fig. 11), and by $45 \%$ when MTs were predominant $\left(t_{12}\right)$ (Fig. 12); no decrease was observed at the time of schizogony $\left(t_{0}\right)$ (Fig. 13).

\section{P. CHABAUDI CHABAUDI: EFFECT ON THE TAIL BLOOD OF A SINGLE INJECTION OF ADRENALIN}

Twenty mice were infected at the same time with frozen aliquots of $P$. chabaudi chabaudi, which is a synchronous species with a schizogonic cycle well known to be set by the circadian rhythm of the host. Adrenalin or saline (controls) was injected at two different times of the day, when a different parasitic 


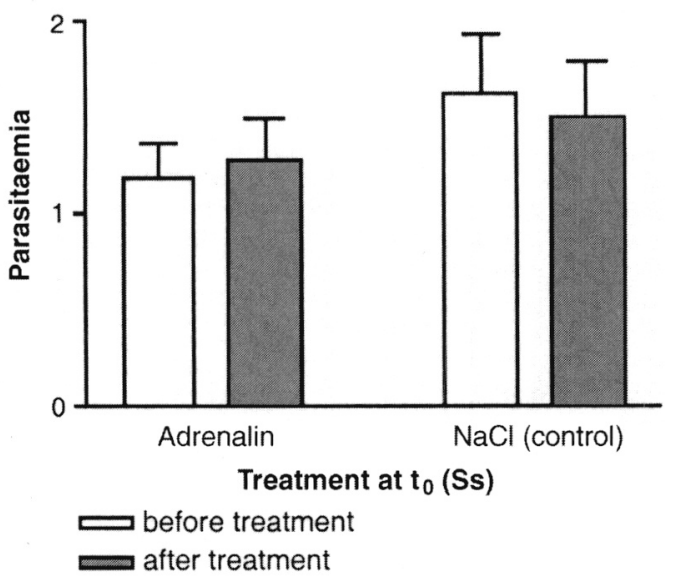

Fig. 13. - P. vinckei petteri: effect of adrenalin injection on parasitaemia in mouse tail blood when schizonts (Ss) are predominant $\left(t_{0}\right)$ Box-plots represent parasitaemias and error bars indicate the SEM.

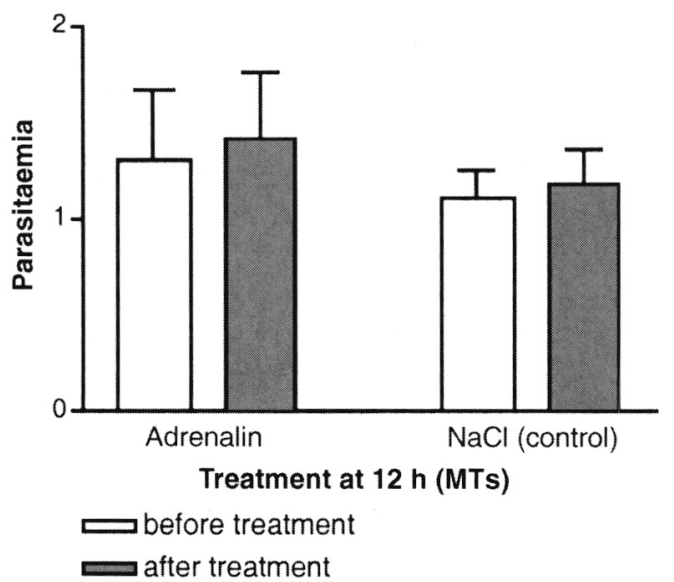

Fig. 14. - P. chabaudi chabaudi: effect of adrenalin injection on parasitaemia in mouse tail blood when midterm trophozoites (MTs) are predominant (12:00 hours)

Box-plots represent parasitaemias and error bars indicate the SEM

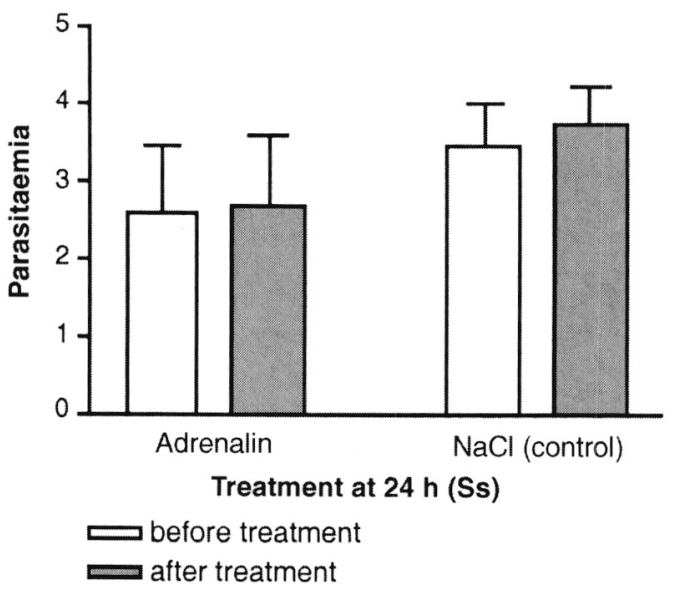

Fig. 15. - P. chabaudi chabaudi: effect of adrenalin injection on parasitaemia in mouse tail blood when schizonts (Ss) are predominant (midnight).

Box-plots represent parasitaemias and error bars indicate the SEM. stage was predominant. Parasitaemias were estimated in tail blood before and one minute after the injections. Experiments were performed at day 10 after inoculation, the injections being given $i$ ) at midnight when Rs and Ss were predominant together with many Ots, and $i$ ) at 12:00 hours when MTs were predominant. Parasitaemias remained constant before and after treatment (Figs 14, 15).

\section{DISCUSSION}

The development of the malaria parasite inside the erythrocyte induces increased rigidity of the cell, lower deformability and increased adhesiveness of erythrocytes to other cells, particularly the vascular endothelium (Miller et al., 1972; Paulitschke \& Nash, 1993; Dondorp et al., 2000; Cooke et al., 2001). Adrenalin almost instantly causes a large part of the peripheral blood to be diverted to the major organs; it is interesting to note that not all stages of the parasite are affected to the same extent.

Because of its asynchronous schizogonic cycle in the blood, P. yoelii was considered to be the most suitable rodent species for this study, for the following reasons: i) different stages are present at the same time, and the evaluation of the parasitic pattern permits the determination of which stage is the most affected by the adrenalin injection; $i$ ) the parasite shows a preference for reticulocytes and, as it grows, enlarges the host cell. In order to avoid the increasing number of multiparasitized reticulocytes which appear during the course of the infection, most experiments were performed when parasitaemias were below $2 \%$.

Comparisons were made with two other species: P. vinc$k e i$, which fills the normocyte in which it develops, and $P$. chabaudi, a much smaller parasite.

With $P$. yoelii, one minute after the injection there was, in the peripheral circulation of the large vessels of the tail as well as in the mosquito blood meal drawn from capillaries, a sudden decrease of parasitaemia, associated with a decrease of Rs + Yts and particularly of MTs. These stages, being small, appear not to be held in the peripheral capillaries while the older parasites (OTs) are less mobile and are retained.

These conclusions were confirmed by the results of experiments with $P$. vinckei, a species with a synchronous cycle in the blood. The administration of adrenalin at different times of the cycle produced a significant diminution of parasitaemia only when MTs and, to a lesser extent Rs + YTs, were predominant. The opposite occurred in the right heart, and presumably in other organs. Parasitaemia was lower than in tail blood and the adrenalin injection was followed by increased parasitaemia and an influx of MTs. 
To understand the differential effect on MTs, two factors must be considered: $i$ ) the parasite's size and ii) the erythrocyte's flexibility, essential for ease of circulation:

\section{- (i) Parasite size}

The involvement of parasite size was evidenced by experiments with the synchronous $P$. chabaudi, a much smaller parasite than the other rodent species. Adrenalin had no effect on the infection at any time of the cycle, even when MTs were predominant.

- (ii) Flexibility of red blood cell

Although reticulocytes are larger than normocytes, adrenalin did not modify the reticulocytaemia in uninfected mice, which indicates that membrane elasticity and viscosity of the cytoplasm are also important factors

The deformability of red blood cells diminishes as the parasite grows (Kaul et al., 1994). It is therefore surprising that the most mobile stages are the MTs and not the Rs + YTs. The logical explanation, in our view, is that MTs by their increased surface area, as compared to rings, and their flexibility which contrasts with the rigid schizonts, are particularly susceptible to haemodynamic perturbations.

Daily injections of adrenaline during the course of infection by $P$. yoelii showed that the drug lost its effect when parasitaemias rose above $5 \%$ and regained it after the crisis when mice were recovering and parasitaemias declined. When parasitaemias are high, the majority of infected red blood cells are polyparasitized reticulocytes of large size and probably increased rigidity, which are therefore less mobile.

Because the speed of the circulation differs in the different viscera, and because parasites themselves are more or less mobile or often even sequestered, it appears that their distribution in the different organs and blood vessels cannot be uniform.

Alger (1963) and Desowitz \& Barnwell (1976) investigated the parasitaemia and the parasitic stages present in impression smears of viscera prepared at autopsy of mice infected with $P$. berghei, and described differences according to the organs. We will not attempt to compare experiments performed in vivo with those done post mortem but we note that they found significant differences of parasitaemia and parasitic pattern in the viscera of mice, and in the organs of different hosts.

Coquelin et al. (1999) showed that the last developmental stage of the rodent malarias in the vertebrate host, the maturation of schizonts and the release of merozoites, occurred in small vessels in the viscera and preferentially in the lungs, where rigid "pillars" slow down the circulation and facilitate the rupture of mature schizonts and the invasion of new red blood cells by the merozoites. They hypothesized that invasion of erythrocytes by merozoites was not likely to occur in the extremely fast circulatory stream and must take place in vessels of small calibre where the blood slows down. This hypothesis is coherent with the observations of Desowitz et al. (1976), who found large numbers of ring forms in the left heart.

The greater rigidity of older stages and the slowing down of the circulation appear to be necessary for the parasites multiplication, the invasion of red blood cells by the parasite, and the completion of the life cycle. Our observations on the selective mobility of young stages - Rs, YTs and MTs - compared to the relative immobility of older parasites, under variable circulatory conditions, support these conclusions.

The fact that midterm trophozoites are transported by the blood stream preferentially to younger stages is probably due to purely rheological phenomena, allowing them to remain free in the flowing blood stream. The increased rigidity of the parasitized $\mathrm{RBC}$ is a general phenomenon. However the effect on the erythrocyte size varies according to the parasite species. P. malariae, because of it's smaller size may behave like $P$. chabaudi, $P$. falciparum a larger parasite which does not modify the RBC like P. vinckei and, P. vivax which hypertropies the RBC like $P$. yoelii.

\section{ACKNOWLEDGEMENTS}

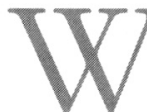

e are much indebted to John Baker and Hagai Ginsburg for their criticisms and helpful suggestions. Stéphane Bertani was awarded a PhD fellowship from the University Pierre et Marie Curie (Paris 6) and the Ministère Délégué à la Recherche.

\section{REFERENCES}

ALGER N.E. Distribution of schizonts of Plasmodium berghei in tissues of rats, mice and hamsters. Journal of Protozoology, 1963, 10, 6-10.

Bruce-Chwatt L.J. Essential Malariology. William Heinemann Medical Books Ltd, London, 1986, 415 p.

Brumpt É. Précis de parasitologie, sixième édition. Masson, Paris, 1949, 2148 p.

Cooke B.M., Mohandas N. \& Coppel R.L. The malaria-infected red blood cell: structural and functionnal changes. Advances in Parasitology, 2001, 50, 1-86.

Coquelin F., Boulard Y., Mora-Silvera E., Richard F., ChaBAUD A.G. \& LANDAU I. Final stage of maturation of the erythrocytic schizonts of rodent Plasmodium in the lungs. Compte Rendus de l'Académie des Sciences, Paris, 1999, 322, 55-62.

Desowitz R.S. \& Barnwell J.W. Plasmodium berghei: deep vascular sequestration of young forms in the heart and kidney of the white rat. Annals of Tropical Medicine and Parasitology, 1976, 70, 475-476. 
Dondorp A.M, Kager P.A., Vreeken J. \& White N.J. Abnormal blood flow and red blood cell deformability in severe malaria. Parasitology Today, 2000, 16, 228-232.

Kaul D.K., Nagel R.L., Llena J.F.F. \& Shear H.L. Cerebral malaria in mice: demonstration of cytoadherence of infected red blood cells and microrheologic correlates. American Journal of Tropical Medicine and Hygiene, 1994, 50, $512-521$

Landau I., Miltgen F., Boulard Y., Chabaud A.G. \& Baccam D. Study of gametocytes from the Plasmodium "vivax" group: morphology, development in Anopheles and infectivity of Plasmodium yoelii microgametocytes. Annales de Parasitologie Humaine et Comparée, 1979, 54, 145-161.

Landau I. \& Chabaud A. Parasitic pattern of rodent Plasmodium in blood from mouse tail and from Anopheles blood meal. Parassitologia, 2002, 44, 111-115.

Marchiafava E. \& Bignami A. Sulle febbri malariche estivoautumnali. Editore Loescher and Co., Rome, 1892.

Miller L.H., Chien S. \& Usami S. Decreased deformability of Plasmodium coatneyi-infected red cells and its possible relation to cerebral malaria. American Journal of Tropical Medicine and Hygiene, 1972, 21, 133-137.

PAulitschke M. \& NASH G.B. Membrane rigidity of red blood cells parasited by different strains of Plasmodium falciparum. Journal of Laboratory Clinical Medicine, 1993, 12, 581-589.

Voza T., Gautret P., Rénia L., Gantier J.C., Lombard M.N., Chabaud A.G. \& Landau I. Variation in murid Plasmodium desequestration and its modulation by stress and pentoxifylline. Parasitology Research, 2002, 88, 344-349.

Vuong P.n., Richard F., Snounou G., Coquelin F., Rénia L. Gonnet F., Chabaud A.G. \& Landau I. Development of irreversible lesions in the brain, heart and kidney following acute and chronic murine malaria infection. Parasitology, $1999,119,543-553$.

Reçu le 8 janvier 2004 Accepté le 12 juillet 2004 